\title{
Prevalence of Bullying and Cyberbullying in the Last Stage of Primary Education in the Basque Country
}

\author{
Juan Manuel Machimbarrena ${ }^{1}$ and Maite Garaigordobil ${ }^{2}$ \\ 1 Universidad Internacional de La Rioja (Spain) \\ 2 Universidad del País Vasco (Spain)
}

\begin{abstract}
Bullying and cyberbullying pose a serious problem in our schools. Despite this research area's increasing relevance, most research into cyberbullying in the present day has focused only on adolescents. However, given the long-lasting effects of victimization, it is necessary to understand its prevalence throughout the different educational stages of students. This study aims to clarify the prevalence of bullying and cyberbullying among students in the $5^{\text {th }}$ and $6^{\text {th }}$ grades. A sample of $1,993\left(M_{\text {age }}=10.68, S D=0.71\right.$; range $\left.9-13\right)$ students completed the "Cyberbullying: Screening of Peer-Harassment" test. The results reveal that $20.3 \%(n=404)$ were pure victims, $6.1 \%(n=121)$ pure bullies, $23.9 \%(n=476)$ bully-victims, and $28.9 \%(n=575)$ pure bystanders of bullying. With respect to cyberbullying, $13.4 \%(n=267)$ were pure cybervictims, $0.7 \%(n=13)$ pure cyberbullies, $3.1 \%$ cyberbully-victims $(n=62)$, and $25.6 \%$ $(n=510)$ pure cyberbystanders. In addition, the results reveal that verbal aggression and offensive or insulting messages were the most prevalent forms of aggression in bullying and cyberbullying, respectively. $36.6 \%$ of the sample had suffered verbal aggression and $8.4 \%$ had received offending or insulting messages. These data show that bullying and cyberbullying are considerably prevalent in this educational stage.
\end{abstract}

Received 24 January 2018; Revised 18 September 2018; Accepted 21 September 2018

Keywords: bullying, children, cyberbullying, prevalence.

Bullying and cyberbullying have been established as global phenomena, occurring at different educational stages (Kowalski, Giumetti, Schroeder, \& Lattanner, 2014). Most studies have focused their analysis on secondary school students and adolescents (Kowalski, Limber, \& McCord, 2018) and, subsequently, the vast majority of prevention and intervention programs also focus on this age group (Della Cioppa, O'Neil, \& Craig, 2015; Ttofi \& Farrington, 2011). The main reason that these studies on cyberbullying have focused on adolescents relies on the assumption that children started to use ICT and smartphones at a later stage. However, data from the Instituto Nacional de Estadística indicate that in $2016,90.6 \%$ and $93.1 \%$ of children aged 10 and 11 respectively were already Internet users.

These data show that children of this age group are already Internet users with all the advantages and risks this entails. According to Kowalksi, Giumetti, Schroeder, and Lattaner (2014) meta-analysis and review, one of the most worrying consequences of bullying and cyberbullying victimization is that it affects several mental health outcomes. This path has been supported by other meta-analyses showing

Correspondence concerning this article should be addressed to Juan Manuel Machimbarrena. Departamento de Personalidad, Evaluación y Tratamiento Psicológico de la Universidad del País Vasco, San Sebastián (Spain).

E-mail: juanmanuel.machimbarrena@ehu.eus

University of the Basque Country (UPV/EHU). PPG17/31. a relationship between bullying and cyberbullying victimization and externalizing (i.e., conduct problems, substance use, self-harm) and internalizing disorders (i.e.: depression, anxiety, physical symptoms) (Fisher, Gardella, \& Teurbe-Tolon, 2016; Gini, Card, \& Pozzoli, 2018), and by longitudinal research, that has shown that victimization can generate harmful long-term consequences (Bannink, Broeren, van De Looij-Jansen, de Waart, \& Raat, 2014; Gámez-Guadix, Orue, Smith, \& Calvete, 2013), and even lead to suicidal ideation (Holt et al., 2015). Furthermore, chronic victimization from early adolescence can be particularly worrying as recent research has showed that victimization can lead adolescents to develop maladaptive schemas that put them at a higher risk for new episodes of victimization and psychological problems (Calvete, FernándezGonzález, González-Cabrera, \& Gámez-Guadix, 2018).

The worrying consequences of bullying and cyberbullying together with the data of Internet use at this age reveal the need to analyze the prevalence of cyberbullying in this age range, as a step toward creating prevention and intervention programs adapted to this developmental period.

How to cite this article:

Machimbarrena, J. M., \& Garaigordobil, M. (2018). Prevalence of bullying and cyberbullying in the last stage of primary education in the Basque Country. The Spanish Journal of Psychology, 21. e48. Doi:10.1017/sjp.2018.41 
For this study, we reviewed the literature on bullying and cyberbullying of children in or near their last stage of primary education (9-13 years old) from the last 5 years. The results of the main prevalences are presented in Table 1.

As can be seen in Table 1, with respect to face-to-face bullying, the percentage of victims ranges from $7 \%$ (Cerezo, Sánchez, Ruiz, \& Arense, 2015; Navarro, Yubero, \& Larrañaga, 2015) to approximately 33\% (Blaya \& Fartoukh, 2016; Leung \& Mcbridge-Chang, 2013; Price, Chin, Higa-McMillan, Kim, \& Frueh, 2013). In the case of bullies, the proportion ranges from $4 \%$ (Iossi-Silva, Pereira, Mendonça, Nunes, \& de Oliveira, 2013; Navarro et al., 2015), to approximately $20 \%$ (García-Fernández, Romera-Félix, \& Ortega-Ruiz, 2016; Leung \& Mcbridge-Chang, 2013; Shujja, Att, \& Shujjat, 2013). It should be noted that Connell, Schell-Busey, Pearce, and Negro (2014) places prevalence at significantly higher percentages, $61 \%$ and $36 \%$ for victims and bullies, respectively. For bully-victims, the range varies from $1.3 \%$ (Cerezo et al., 2015) to $25 \%$ (Shin, Braithwaite, \& Ahmed, 2016). Regarding the studies analyzing severe victimization (i.e., students who suffered bullying behaviors very frequently or always), it ranges from 3.9\% (García-Fernández et al., 2016) to $11.3 \%$ (Chester et al., 2015), while the number of severe bullies' ranges from 1.8\% (Leung \& Mcbridge-Chang, 2013) to 8\% (García-Fernández et al., 2016; Kowalski \& Limber, 2013). Fewer studies report the number of bystanders; however, García-Fernández et al. (2016) report that $28 \%$ of children were bystanders of faceto-face bullying. In a study involving adolescents, Garaigordobil (2015) reports a slightly higher percentage of $33.7 \%$ of adolescents who observed bullying without being involved either as victims or bullies.

When considering cyberbullying, the prevalence of cybervictims ranges from 3\% (Jung et al., 2014; Navarro et al., 2015) to $52 \%$ (Blaya \& Fartoukh, 2016), and the number of cyberbullies ranges from 1\% (Navarro et al., 2015; Shin et al., 2016) to 14\% (Connell et al., 2014; Fletcher, Fitzgerald-Yau, Jones, Allen, Viner, \& Bonell, 2014). Regarding cyberbully-victims, the prevalence ranges from 1\% (Shin et al., 2016) to 5\% (Kowalski \& Limber, 2013; Rice et al., 2015), although the study by Kokkinos, Antoniadou, Dalara, Koufogazou, and Papatziki (2013) reports a rate of $19 \%$ of cyberbullyvictims. Those studies that analyze severe cybervictimization and severe cyber-aggression place the percentage of severe cybervictims between $4 \%$ (IrakasSistema Ebaluatu eta Ikertzeko Erakundea-Instituto Vasco de Evaluación e Investigación Educativa, ISEIIVEI, 2017) (Kowalski \& Limber, 2013) and 13.9\% (Blaya \& Fartoukh, 2016), and that of severe cyberbullies around 3\% (Kowalski \& Limber, 2013; Leung \& Mcbridge-Chang, 2013). As for cyberbystanders, the range is between $13 \%$ of bystanders (García-Fernández et al., 2016) and $28.8 \%$ (Pabian et al., 2016).

In regard to the most frequent behaviors, several studies confirm that physical aggressions begin to decrease around the age of 10-11, while verbal and relational aggressions become more frequent (Garaigordobil, 2017). In addition, several studies have found that verbal offenses are the most frequent behaviors in the last stage of primary school, followed by social aggressions (Connell et al., 2014; ISEI-IVEI, 2017) or physical assaults (Price et al., 2013). Given the distinct nature of the behaviors analyzed in the different studies, determining the most frequent cyberaggression is hard. However, a review of the studies conducted points to offensive and insulting messages, insulting calls, anonymous calls, and the spread of rumors as the most frequent forms of attack (Blaya \& Fartoukh, 2016; Garaigordobil, 2013, 2015).

Of note is the inclusion of the study of Garaigordobil's $(2013,2015)$ with an older sample (aged 12 to 18$)$, as it uses the same structure, instrument and setting as this study and will allow for a comparison between our sample of last stage primary education and her study, with secondary and baccalaureate students.

As shown in Table 1, few studies focus only on primary school students, generally using older participants as part of the sample. In addition, there are large differences in prevalence rates, due to the different instruments used and the different time ranges analyzed. Finally, it can also be observed that hardly any studies provide data on the 4 roles (victim, bully, bullyvictim, and bystander) of bullying and cyberbullying.

\section{Objectives and Hypotheses}

The main aim of the study is to analyze the global and severe prevalence of bullying and cyberbullying in the last stage of primary education. With this objective, and based on the review of previous studies and their prevalence rates presented in Table 1 and the study of Garaigordobil $(2013,2015)$ with secondary education students, the following 5 hypotheses are proposed:

a. In terms of global bullying, we expect to find that around $20 \%-25 \%$ of students will be pure victims, $5 \%-10 \%$ will be pure bullies, $10 \%-15 \%$ will be bullyvictims, and $35 \%$ will be pure bystanders.

b. Regarding severe bullying or actual bullying (defined as occurring "often" and "always," respectively), the expected percentages are that $10 \%$ of students will be severe pure victims, 3\% will be severe pure bullies and severe bully-victims, and $20 \%$ will be severe pure bystanders who will have frequently observed aggressive behaviors among peers over the past year. 
Table 1. Review of Prevalence Studies in Children of Equivalent Age or Close to those in Lower Primary Education

\begin{tabular}{|c|c|c|c|c|c|c|c|c|c|}
\hline Reference & Location & $N$ (Age range) & $\% \mathrm{~V}$ & $\% \mathrm{~B}$ & $\% \mathrm{BV}$ & $\% \mathrm{CBV}$ & $\%$ CBB & $\%$ CBBV & Time parameter \\
\hline Iossi-Silva et al. (2013) & Brazil & $387(8-12)$ & $18.5^{\mathrm{a}}$ & $5.8^{\mathrm{a}}$ & $5^{\text {a }}$ & & & & $2-3$ months \\
\hline Kokkinos et al. (2013) & Greece & $300(10-12)$ & & & & $11.3^{\mathrm{a}}$ & $6^{a}$ & $19^{a}$ & Month \\
\hline Kowalski and Limber (2013) & United States & $913(11-17)$ & $14.6^{\mathrm{a}}(8.4)$ & $17.3^{\mathrm{a}}(8.2)$ & $19.2^{\mathrm{a}}(3.7)$ & $9.9(4)^{\mathrm{a}}$ & $6.1^{\mathrm{a}}(2.5)$ & $5.3^{\text {a }}(1.9)$ & $2-3$ months \\
\hline $\begin{array}{l}\text { Leung and Mcbridge-Chang } \\
\text { (2013) }\end{array}$ & China & $626(10-11)$ & $36.1(6.5)$ & $21.9(1.8)$ & & $16.3(5.3)$ & $12.2(4)$ & & \\
\hline Price et al. (2013) & Hawaii & $211(10-13)$ & 32.7 & 9 & & 7 & 4 & & $2-3$ months \\
\hline Bannink et al. (2014) & The Netherlands & 3,181 (mean 12.47) & 21.4 & & & 5.1 & & & Month \\
\hline Connell et al. (2014) & United States & $3,867(10-14)$ & 61 & 36 & & 25 & 13.8 & & Three months \\
\hline Fletcher et al. (2014) & United Kingdom & $1,144(12-13)$ & & & & & 14.1 & & Life-span \\
\hline Jung et al. (2014) & South Korea & $2,108(11-12)$ & & & & $3.3^{\mathrm{a}}$ & $3.4^{\mathrm{a}}$ & $3.0^{\mathrm{a}}$ & Six months \\
\hline Shujja et al. (2014) & Afghanistan & $839(10-14)$ & 24.1 & 23.2 & & & & & Month \\
\hline Cerezo et al. (2015) & Spain & 847 (mean 12.73) & 6.8 & 8.1 & 1.3 & & & & \\
\hline Chester et al. (2015) & Transcultural & $838(11,13,15)$ & $29.2(11.3)$ & & & & & & $2-3$ months \\
\hline DePaolis and Williford (2015) & United States & $660($ mean 9.5$)$ & & & & $17.7(11)$ & & & \\
\hline $\begin{array}{l}\text { Fernández-Montalvo, Peñalva, } \\
\text { and Irazabal (2015) }\end{array}$ & Spain & $364(10-13)$ & & & & 13,7 & 12.3 & & Life-span \\
\hline Garaigordobil $(2013,2015)$ & Spain & $3,026(12-18)$ & 11.6 & 11.3 & 27.1 & 19.6 & 4.9 & 10.6 & Year \\
\hline $\begin{array}{l}\text { Guilheri, Cogo-Moreira, } \\
\text { Kubiszewski, Yazigi, } \\
\text { and Andronikof (2015) }\end{array}$ & France & $802(9-12)$ & 26.8 & 5.6 & 14.6 & & & & $2-3$ months \\
\hline Navarro et al. (2015) & Spain & 1,058 (10-12) & 8.9 & 3.6 & & 2.9 & 1.2 & & Three months \\
\hline Rice et al. (2015) & United States & $1,185(10-14)$ & & & & 6.6 & 5 & 4.3 & Year \\
\hline Blaya and Fartoukh (2016) & France & $417(8-11)$ & $31.4(7.2)$ & $(5.5)$ & & $52(13.9)$ & & & Six months \\
\hline García-Fernández et al. (2016) & Spain & 1,278 (mean 11.11) & $12.40(3.9)$ & $19.9(7.8)$ & $15.4(2.2)$ & 9.3 & 5.5 & 3.4 & Three months \\
\hline $\begin{array}{l}\text { Pabian, Vandebosch, Poels, } \\
\text { Van Cleemput, and } \\
\text { Bastiaensens (2016) }\end{array}$ & Belgium & $1,412(10-13)$ & & & & 13 & 10 & & Six months \\
\hline Shin et al. (2016) & Australia & $3,956(12-13)$ & $29^{a}$ & $6^{\mathrm{a}}$ & $25^{a}$ & $6^{\mathrm{a}}$ & $0.7^{\mathrm{a}}$ & $1^{\mathrm{a}}$ & Month \\
\hline ISEI-IVEI (2017) & Spain & $5,962(8-13)$ & 22.7 & & & $12.5(3.3)$ & & & School year \\
\hline
\end{tabular}

Note: $\% \mathrm{~V}=$ victims; $\% \mathrm{~B}=$ bullies; $\% \mathrm{BV}=$ bully-victims; $\% \mathrm{CBV}=$ cybervictims; $\% \mathrm{CBB}=$ cyberbullies; \%CBBV = cyberbully-victims.

${ }^{a}=$ denotes that the victim, bully and bully-victim categories are mutually exclusive; parenthesis indicates severe implication. 
c. With regard to cyberbullying, we expect that $10 \%-$ $15 \%$ of students will be pure victims, 3\%-5\% will be pure cyberbullies, $5 \%-7 \%$ will be cyberbullyvictims, and $30 \%-40 \%$ of the participants will have been pure bystanders of cyberbullying behaviors over the last year.

d. For severe cyberbullying, it is proposed that approximately $3 \%$ of the student sample will be severe cyber victims, $1 \%$ will be severe pure cyberbullies or severe cyberbully-victims, and around $10 \%$ will be severe bystanders of cyberbullying behaviors among equals.

e. The most frequently reported aggressive face-to-face bullying behaviors are expected to be verbal and physical aggression, while for cyberbullying, the most frequent behaviors are expected to be offensive and insulting messages, offensive and insulting calls, and anonymous calls made to provoke fear.

\section{Method}

\section{Participants}

The study sample included 1,993 students in $5^{\text {th }}$ and $6^{\text {th }}$ grades. The randomly selected children make up a representative sample of pupils in the last stage of primary school in the Basque Country. Participants were aged between 9 and 13 years old $(M=10.68, S D=0.71)$, $50.2 \%$ boys and $48.8 \%$ girls. $51.5 \%(n=1,027)$ were in the $5^{\text {th }}$ grade and $48.5 \%$ were in the $6^{\text {th }}$ grade $(n=966)$. $51 \%$ of the sample attended public network schools (13 schools) and the remaining $49 \%$ attended private or concerted schools (12 schools). For the selection, the population level of the provinces of the Basque Country (Gipuzkoa, Bizkaia and Araba) was taken into account. Of the 1,993 participants, $16.3 \%$ attended schools in the province of Araba, 46.9\% attended schools in the province of Bizkaia, and the remaining $36.9 \%$ attended schools in Gipuzkoa.

\section{Instruments}

To evaluate the variables under study, the "Cyberbullying: Screening of Peer-Harassment" (Garaigordobil, 2013) test was applied. This standardized instrument, with psychometric guarantees of reliability and validity, evaluates both face-to-face bullying and cyberbullying. It provides 4 indicators: Level of victimization, aggression, aggressive-victimization, and observation. The Bullying Scale through a four item scale, assesses four types of bullying: Physical aggression (aggressive actions aimed at a person's body, e.g. hit, push, slap...; or indirect actions, aimed at their property, e.g. steal or damage the books, backpack); verbal aggression (negative verbal behaviors towards someone, e.g. insults, calling him or her hurtful names...); social aggression (behaviors that isolate a person from the group, e.g. ignoring the victim and excluding him or her from normal social interactions); and psychological aggression (bullying behaviors to undermine a person's self-esteem and provoke insecurity and fear, e.g. humiliating the victim or creating insecurity for him or her). The Cyberbullying Scale explores the roles of cybervictim, cyberbully and cyberbystander 15 behaviors related to technological bullying such as: Making offensive calls, making anonymous to calls to frighten, sending offensive and insulting messages, recording a beating and uploading it to YouTube, stealing and uploading private or compromising photos, blackmailing or threatening someone, spreading rumors, secrets, and lies, faking photos or videos and uploading them to YouTube, isolating others in social networks, blackmailing with disclosing intimate details about someone, slandering, impersonation, death threats, sexual harassment.

The 4 items of the bullying scale and the 15 items are phrased in the victim role (e.g. "Have you been blackmailed or threatened with calls or messages during the last year?"), and then in the bully role (e.g. "Have you blackmailed or threatened another student with calls or messages during the last year?"), and finally, in the bystander role (e.g. "Have you witnessed another student being threatened with calls or messages during the last year?"). In both scales participants report the frequency with which they have suffered, performed and observed those behaviors (Likert scale of $0=$ never, 1 = sometimes, 2 = often, 3 = always) during the last year.

The psychometric analyses in this sample confirm adequate internal consistency on both the bullying scale (global scale $\alpha=$. 84; victimization $\alpha=.80$; aggression $\alpha=.69$; and observation $\alpha=.84$ ) and on the cyberbullying scale (global scale $\alpha=.91$; cyber-victimization $\alpha=$. 83; cyber-aggression $\alpha=.91$; cyberobservation $\alpha=.89$ ). Exploratory factor analysis confirmed a threefactor structure (victims, aggressors, bystanders) on both scales that explains $61.61 \%$ and $43.72 \%$ of the variance for bullying and cyberbullying, respectively. The assessment tool also showed convergent validity yielding positive correlations between aggression and aggressive conflict resolution, antisocial behavior, psychopathological disorders, school problems, neuroticism, and negative correlations with empathy, emotional regulation, responsibility as well as social adaptation in the original sample (Garaigordobil, 2013).

\section{Design and procedure}

This research used a descriptive and comparative cross-sectional design. With regard to the procedure, firstly an e-mail was sent to the randomly selected schools to explain the research, afterwards a telephone 
or personal interview was set to further the information and clarify the queries of the school staff. Once the school agreed to participate consent forms were sent to parents and students via school administration and a date was set for completing the cyberbullying test. After informed consent of school administration, the parents, and the students were obtained, the test was administered in a 45 -minute session by members of the research team, who presented the standardized instructions and gave the questionnaire to the participants. They completed the test in a classroom, in a group setting. Even though most of the students in the classrooms participated, under the Organic Law on the Protection of Personal Data (LOPD), several institutions did not provide the number of students who did not agree to participate in the research.

The study complied with the with the ethical values required in research involving human beings, respecting the fundamental principles included in the Helsinki Declaration (informed consent and right to information, protection of personal data and guarantees of confidentiality, non-discrimination, gratuity and the right to withdraw from the study in any of its stages), receiving a favorable report from the ethics committee of the University of the Basque Country (CEISH/229/2013). After collecting the data, an individual report was sent to each school providing information on the prevalence of the school and of the autonomous community.

\section{Data analysis}

First, the frequencies and percentages of students who were victims, perpetrators and bystanders of face-toface bullying were calculated according to 4 mutually exclusive categories: "Pure victims", "pure bullies", "bully-victims", (those who had been victims and also aggressors) and "pure bystanders" (had not performed or suffered aggressions but had observed them between their peers). Taking these categories into account, the global prevalence (i.e. suffered/ perpetrated/witnessed one or more behaviors sometimes, often and always during the past year) and the severe prevalence (i.e. suffered/perpetrated/witnessed one or more behaviors often and always during the past year) of both bullying and cyberbullying is identified. Lastly, the frequency and percentage of victims, bullies and bystanders of the different types of aggressive behavior analyzed is reported.

\section{Results}

\section{Global and severe bullying and cyberbullying prevalence}

The descriptive analyses (frequencies and percentages) (see Table 2) revealed that with respect to face-to-face
Table 2. Global and Severe Prevalence in Bullying and Cyberbullying

\begin{tabular}{|c|c|c|}
\hline & Global & Severe \\
\hline & $f(\%)$ & $f(\%)$ \\
\hline \multicolumn{3}{|l|}{ Bullying } \\
\hline Pure victim & $404(20.3)$ & $263(13.2)$ \\
\hline Pure bully & $121(6.1)$ & $32(1.6)$ \\
\hline Bully-victim & $476(23.9)$ & $40(2.0)$ \\
\hline Pure bystander & $575(28.9)$ & $463(23.2)$ \\
\hline \multicolumn{3}{|l|}{ Cyberbullying } \\
\hline Pure cybervictim & $267(13.4)$ & $58(2.9)$ \\
\hline Pure cyberbully & $13(0.7)$ & $5(0.3)$ \\
\hline Cyberbully-victim & $62(3.1)$ & $3(0.2)$ \\
\hline Pure cyberbystander & $510(25.6)$ & $125(6.3)$ \\
\hline
\end{tabular}

Note: $f=$ frequency; $\%=$ percentage.

bullying: $20.3 \%$ of the sample were pure victims; $6.1 \%$ were pure bullies; $23.9 \%$ were bully-victims; and $28.9 \%$ had observed bullying behaviors in the last year, without having suffered or performed them. In terms of severe prevalence: $13.2 \%$ of the sample were severe pure victims of face-to-face bullying; $1.6 \%$ were severe pure bullies; $2 \%$ were severe bully-victims; and 23.2\% of the sample observed fairly often or always aggressive behaviors among partners in the last year, without having been either a victim or a perpetrator.

When analyzing cyberbullying, we found that $13.4 \%$ of the sample were pure cybervictims, $0.7 \%$ were pure cyberbullies, $3.1 \%$ were cyberbully-victims, and $25.6 \%$ had observed or had knowledge of one or more aggressive cyberbullying behaviors among peers. In terms of cyberbullying at a severe level, the results show that $2.9 \%$ were severe pure cybervictims, $0.3 \%$ were severe pure cyberbullies, $0.2 \%$ were severe cyberbully-victims, and that $6.3 \%$ of the sample had observed cyberbullying behaviors quite often or always among peers in the past year.

\section{Percentages and frequencies of victims, aggressors and bystanders in bullying and cyberbullying behaviors}

With respect to the percentage of those involved in each of the face-to-face bullying behaviors, the results in Table 3 show that the most prevalent aggressions are verbal aggressions, both in global and severe form. In addition, victims, aggressors and bystanders agree and report that physical aggressions are the second most frequent behavior, followed by social aggressions and finally psychological aggressions.

Regarding cyberbullying, as can be seen in Table 4, the comparison of the information from the 3 roles indicates that the 5 most prevalent behaviors are the 
following: offensive and insulting messages and calls to scare and frighten; blackmail or threats through calls or the Internet; defamation by telling lies over the Internet about a person in order to disregard the rights of others.

\section{Discussion}

This study aimed to analyze the prevalence of bullying and cyberbullying among students in the last stage of primary education.

The results showed that $20.3 \%$ of the students were pure victims, $6 \%$ pure bullies, $23.9 \%$ bullyvictims, and $28.9 \%$ bystanders. In this way, hypothesis 1 was supported almost entirely, and the results confirmed the review carried out in international studies. Specifically, similar percentages of victims were found in Bannink et al. (2014) and ISEI-IVEI (2017), and several studies found similar percentages of bullies involved in face-to-face bullying (Cerezo et al., 2015; Shin et al., 2016). The percentage of bully-victims found in this study is similar to that of Shin et al. (2016), who found $25 \%$, but higher than those reported by most studies, which overall reported figures below 15\% (García-Fernández et al., 2016; Guilheri et al., 2015), as well as studies that found percentages below 5\% (Cerezo et al., 2015). Finally, the percentage of bystanders is similar to that reported by García-Fernández et al. (2016), who found $28.45 \%$ of bystanders.

Regarding Hypothesis 2 on the severe prevalence of bullying, the results reveal the existence of $13.2 \%$ severe pure victims, $1.6 \%$ severe pure bullies, $2 \%$ severe bully-victims, and $23.2 \%$ pure bystanders who have observed these aggressive face-to-face behaviors very frequently. Therefore, Hypothesis 2 is confirmed and consistent with the results of other studies that have analyzed the percentage of severe victims of bullying, such as Chester et al. (2015), who found $11.3 \%$ were severe victims, Leung and McBridgeChan (2013), who found 1.8\% were severe aggressors, and Kowalski and Limber (2013), who found 3.7\% were severe bully-victims.

Regarding the prevalence of cyberbullying, Hypothesis 3 is partially confirmed as the numbers of pure cybervictims (13.4\%) and pure cyberbystanders $(25.6 \%)$ are similar to those expected; however, the numbers of pure cyberbullies and cyberbullyvictims are lower, at $0.7 \%$ and $3.1 \%$, respectively. This percentage of cybervictims coincides with the results of other studies (Fernández-Montalvo et al., 2015; ISEI-IVEI, 2017; Kokkinos et al., 2013). The prevalence of cyberbullies in this study is lower than that found by most studies, which have reported a prevalence of around 3\% (Jung et al., 2014; Price et al., 2013; 
Table 4. Frequencies and Percentages of Cybervictims, Cyberbullies and Cyberbystanders of the 15 Cyberbullying Behaviors

\begin{tabular}{|c|c|c|c|c|c|c|c|c|c|c|c|c|}
\hline \multirow[b]{3}{*}{ Item } & \multicolumn{4}{|c|}{ Cybervictims } & \multicolumn{4}{|l|}{ Cyberbullies } & \multicolumn{4}{|c|}{ Cyberbystanders } \\
\hline & $\mathrm{N}$ & $\mathrm{S}$ & $\mathrm{O}$ & A & $\mathrm{N}$ & S & $\mathrm{O}$ & $\mathrm{A}$ & $\mathrm{N}$ & $\mathrm{S}$ & $\mathrm{O}$ & $\mathrm{A}$ \\
\hline & $f(\%)$ & $f(\%)$ & $f(\%)$ & $f(\%)$ & $f(\%)$ & $f(\%)$ & $f(\%)$ & $f(\%)$ & $f(\%)$ & $f(\%)$ & $f(\%)$ & $f(\%)$ \\
\hline 1 & 1,827 (91.6) & $149(7.5)$ & $17(0.9)$ & $0(0.0)$ & $1,946(97.7)$ & $43(2.2)$ & $2(0.1)$ & $2(0.0)$ & $1,587(79.7)$ & 337 (16.9) & $59(3.0)$ & $7(0.4)$ \\
\hline 2 & 1,941 (97.4) & $44(2.2)$ & $8(0.4)$ & $0(0.0)$ & $1,975(99.1)$ & $14(0.7)$ & $1(0.1)$ & $1(0.1)$ & $1,749(87.9)$ & $213(10.7)$ & $24(1.2)$ & $4(0.2)$ \\
\hline 3 & $1,962(98.4)$ & $29(1.5)$ & $2(0.1)$ & $0(0.0)$ & $1,982(99.5)$ & $8(0.4)$ & $1(0.1)$ & $1(0.0)$ & $1,818(91.3)$ & $142(7.1)$ & $23(1.2)$ & $7(0.4)$ \\
\hline 4 & $1,958(98.2)$ & $32(1.6)$ & $3(0.2)$ & $0(0.0)$ & $1,986(99.7)$ & $4(0.2)$ & $1(0.1)$ & $1(0.0)$ & $1,818(91.3)$ & $152(7.6)$ & $17(0.9)$ & $3(0.2)$ \\
\hline 5 & $1,979(99.3)$ & $11(0.6)$ & $3(0.2)$ & $0(0.0)$ & $1,985(99.7)$ & $4(0.2)$ & $2(0.1)$ & $2(0.0)$ & $1,865(93.7)$ & $113(5.7)$ & $8(0.4)$ & $4(0.2)$ \\
\hline 6 & $1,883(94.4)$ & $93(4.7)$ & $14(0.7)$ & $3(0.2)$ & $1,973(99.1)$ & $18(0.8)$ & $0(0.0)$ & $0(0.0)$ & $1,779(89.4)$ & $178(8.9)$ & $27(1.4)$ & $6(0.3)$ \\
\hline 7 & 1,912 (95.9) & $68(3.4)$ & $11(0.6)$ & $2(0.1)$ & $1,973(99.0)$ & $17(0.9)$ & $1(0.1)$ & $1(0.0)$ & $1,792(90.1)$ & $172(8.6)$ & $18(0.9)$ & $8(0.4)$ \\
\hline 8 & 1,963 (98.5) & $24(1.2)$ & $6(0.3)$ & $0(0.0)$ & $1,984(99.6)$ & $4(0.2)$ & $2(0.1)$ & $2(0.1)$ & $1,898(95.3)$ & 77 (3.9) & $12(0.6)$ & $3(0.2)$ \\
\hline 9 & 1,961 (98.3) & $28(1.4)$ & $3(0.2)$ & $1(0.1)$ & 1,985 (99.6) & $5(0.3)$ & $1(0.1)$ & $1(0.0)$ & $1,889(94.8)$ & $91(4.6)$ & $9(0.5)$ & $1(0.1)$ \\
\hline 10 & $1,921(96.4)$ & $62(3.1)$ & $8(0.4)$ & $2(0.1)$ & $1,981(99.4)$ & $9(0.5)$ & $1(0.1)$ & $1(0.0)$ & $1,839(92.4)$ & $127(6.4)$ & $20(1.0)$ & $4(0.2)$ \\
\hline 11 & 1,979 (99.2) & $13(0.7)$ & $1(0.1)$ & $0(0.0)$ & $1,987(99.7)$ & $2(0.1)$ & $1(0.1)$ & $1(0.1)$ & $1,861(93.4)$ & $113(5.7)$ & $11(0.6)$ & $5(0.3)$ \\
\hline 12 & $1,966(98.6)$ & $24(1.2)$ & $3(0.2)$ & $0(0.0)$ & $1,987(99.7)$ & $3(0.2)$ & $1(0.1)$ & $1(0.0)$ & $1,890(94.9)$ & $87(4.4)$ & $8(0.4)$ & $5(0.3)$ \\
\hline 13 & 1,962 (98.4) & $25(1.3)$ & $6(0.3)$ & $0(0.0)$ & $1,986(99.7)$ & $4(0.2)$ & $1(0.1)$ & $1(0.0)$ & $1,871(94.0)$ & $100(5.0)$ & $13(0.7)$ & $6(0.3)$ \\
\hline 14 & 1,951 (97.9) & $34(1.7)$ & $6(0.3)$ & $2(0.1)$ & $1,987(99.7)$ & $3(0.2)$ & $1(0.1)$ & $1(0.0)$ & $1,867(93.8)$ & $106(5.3)$ & $15(0.8)$ & $2(0.1)$ \\
\hline 15 & 1,916 (96.1) & $62(3.1)$ & $15(0.8)$ & $0(0.0)$ & $1,986(99.7)$ & $4(0.2)$ & $1(0.1)$ & $1(0.0)$ & $1,821(91.5)$ & $141(7.1)$ & $20(1.0)$ & $8(0.4)$ \\
\hline
\end{tabular}

Note: 15 cyberbullying behaviors. 1 = Offensive/insulting messages; 2 = Offensive/insulting calls; $3=$ Attacking, recording and hanging on Internet; 4 = Broadcasting private photos/videos; 5 = Taking photos in dressing rooms, beach...to broadcast; $6=$ Anonymous frightening calls; $7=$ Threatening by calls or messages; $8=$ Sexual harassment by cellphone $/$ Internet; $9=$ Identity theft; 10 = Theft of password; 11 = Touching up photos/videos and broadcasting them; 12 = Isolating on social networks; $13=$ Blackmailing by threatening to broadcast intimacy; $14=$ Death threats; $15=$ Slandering and spreading rumors to discredit someone. $\mathrm{N}=$ Never $; \mathrm{S}=$ Sometimes $; \mathrm{O}=$ Often; $\mathrm{A}=$ Always $;=$ frequency, $\%=$ percentage.

Rice et al., 2015). Even so, the percentage of cyberbullies found in this study is similar to that found in several other studies such as Navarro et al. (2015), which found $1.2 \%$ of cyber-aggressors, and Shin et al. (2016), which found $0.7 \%$ of cyberbullies in Australia. On the other hand, the percentage of cyberbully-victims found in our study is similar to that found by other studies such as that of García-Fernández et al. (2016) or Jung et al. (2014), which found $3.4 \%$, and $3 \%$, respectively. However, these results were also lower than in several other studies. Regarding the number of bystanders identified, Pabian et al. (2016) found a $28.8 \%$ of cyberbystanders in their studies, matching the present study. Similarly, Garaigordobil $(2013,2015)$ found $34.7 \%$ were cyberbystanders in a study with adolescents.

Concerning the prevalence of severe cyberbullying, the results reveal that $2.9 \%$ of the sample were severe pure cybervictims, $0.3 \%$ were severe pure cyberbullies, $0.2 \%$ were severe cyberbully-victims, and $6.3 \%$ were cyberbystanders who have observed cyberbullying behavior very frequently. Hypothesis 4 was confirmed, as we found similar percentages to those predicted in the 4 roles. These figures are slightly lower than those of other reviewed studies with adolescents that found about $5 \%$ were severe cybervictims (Kowalski \& Limber,
2013; Leung \& McBridge-Chang, 2013; Garaigordobil, $2013,2015)$, but are similar to those found by ISEI-IVEI (2017), which found 3.3\% were severe cybervictims in the last stage of primary education. Regarding the number of severe cyberbullies and severe cyberbullyvictims, the figures are also lower than in studies that analyzed these involvement categories (Kowalski \& Limber, 2013; Leung \& McBridge-Chang, 2013), which found between $2.5 \%$ and $4 \%$ were severe cyberbullies, or Kowalski and Limber (2013), which found 1.9\% were severe cyberbully-victims.

Finally, as regards the most frequent behaviors, victims, aggressors, and bystanders agreed that in face-toface bullying the most prevalent forms of aggression are verbal, whereas the second most frequent are physical. Regarding the most prevalent cyberbullying attacks, cybervictims, cyberbullies, and cyberbystanders agreed that offensive and insulting messages and calls to scare and frighten are the 2 most frequent behaviors. Therefore, Hypothesis 5 was completely confirmed.

These results agree with several studies pointing to verbal aggression as being the most common form of aggression (Price et al., 2013), but contrast with Williams and Guerra (2007), who indicated that physical aggression was more prevalent than verbal aggression. 
This difference may be due to the mean age of the samples under study, which were slightly lower than the mean age of this study, as the literature confirms the predominance of physical bullying at younger ages (Garaigordobil, 2017). As for cyberbullying, the behaviors analyzed in other research (e.g., e-mail, SMS text messages, specific social media, etc.) differ from those studied here, thus making it difficult to compare results; however, they point in the same direction as Garaigordobil's $(2013,2015)$ studies, which also found these behaviors were the most prevalent among adolescents and young people in the Basque Country, and other international studies (e.g. Blaya \& Fartoukh, 2016).

These results imply that, although the prevalence of cyberbullying is less frequent than that of face-to-face bullying, it is a real problem in this educational stage, even at a severe level. For this reason, and because of the effects of victimization on children's and adolescents' mental and physical health outcomes such as higher levels of depression, anxiety, loneliness, psychosomatic complaints and lower self-esteem and academic performance among others (Garaigordobil, 2017; Kowalski et al., 2018), it is important to create and implement programs for the prevention and intervention of bullying and cyberbullying in order to teach children the risks and implications of using communication technologies, as well as teaching them strategies to deal with situations of cyberattacks, either as a cybervictim or as a bystander.

It should be noted that, although there are empirically validated bullying and cyberbullying prevention programs, they have usually been oriented toward secondary school students. For this reason, it is necessary to create new content or adapt existing programs for these ages and this developmental stage. This will also result in greater prevention, since, as the metaanalyzes of Yeager, Fong, Lee, and Espelage (2015) show, the effect of the programs is greater when conducted with those aged younger than 12-13 than with those older than 12-13 years of age.

Finally, this study is not exempt from limitations, in particular the use of self-reporting with the social desirability bias that entails. In addition, although the sample is representative of the Basque Country, it would be useful to carry out prevalence studies in other geographical settings. Furthermore, another limitation comes from not gathering data on the use of ICT from the participants, doing that would have permitted to run comparisons between the data on use of ICT form the Instituto Nacional de Estadística and our sample, and between users and non-users of Internet and the different roles of cyberbullying. In spite of these limitations, this study makes a significant contribution by providing prevalence data on the different roles involved in bullying and cyberbullying in an educational stage that has been understudied until now but that, according to the studies analyzed here, is as likely to be cybervictimized as secondary school students. For this reason, the main objective of any future research work must be to create prevention and intervention plans with appropriate content adapted to this educational stage.

In this sense, in addition to the already mentioned bullying and cyberbullying interventions, programs that promote improvement in the social climate of the classroom, respect for difference, enhanced empathy and emotional expression, increased self-esteem, more prosocial behavior, cooperative conflict resolution skills, and anger control (Garaigordobil, 2013) should be implemented in schools. In addition, given the vital role that parents and teachers play in the lives of children of this age, it is imperative that future programs involve both the family and the school in tackling these problems.

\section{References}

Bannink R., Broeren S., van de Looij-Jansen P. M., de Waart F. G., \& Raat H. (2014). Cyber and traditional bullying victimization as a risk factor for mental health problems and suicidal ideation in adolescents. PLOS ONE, 9(4), e94026. https:/ / doi.org/10.1371/journal.pone.0094026

Blaya C., \& Fartoukh M. (2016). Digital Uses, Victimization and online aggression: A comparative study between primary school and lower secondary school students in France. European Journal on Criminal Policy and Research, 22(2), 285-300. https: / / doi.org/10.1007/s10610-015-9293-7

Calvete E., Fernández-González L., González-Cabrera J. M., \& Gámez-Guadix M. (2018). Continued bullying victimization in adolescents: Maladaptive schemas as a mediational mechanism. Journal of Youth and Adolescence, 47(3), 650-660. https: / / doi.org/10.1007/s10964-017-0677-5

Cerezo F., Sánchez C., Ruiz C., \& Arense J.-J. (2015). Adolescents and preadolescents' roles on bullying, and its relation with social climate and parenting styles. Revista de Psicodidáctica, 20(1), 139-155. https: / /doi.org/10.1387/ RevPsicodidact.11097

Chester K. L., Callaghan M., Cosma A., Donnelly P., Craig W., Walsh S., \& Molcho M. (2015). Cross-national time trends in bullying victimization in 33 countries among children aged 11, 13 and 15 from 2002 to 2010. European Journal of Public Health, 25(2), 61-64. https:/ / doi. org/10.1093/eurpub/ckv029

Connell N. M., Schell-Busey N. M., Pearce A. N., \& Negro P. (2014). Badgrlz? Exploring sex differences in cyberbullying behaviors. Youth Violence and Juvenile Justice, 12(3), 209-228. https: / / doi.org/10.1177/1541204013503889

della Cioppa V., O’Neil A., \& Craig W. (2015). Learning from traditional bullying interventions: A review of research on cyberbullying and best practice. Aggression and Violent Behavior, 23, 61-68. https://doi.org/10.1016/ j.avb.2015.05.009 
DePaolis K., \& Williford A. (2015). The nature and prevalence of cyber victimization among elementary school children. Child and Youth Care Forum, 44(3), 377-393. https://doi.org/10.1007/s10566-014-9292-8

Fernández-Montalvo J., Peñalva Vélez A., \& Irazabal I. (2015). Internet use habits and risk behaviors in preadolescence. Comunicar, 22(44), 113-121. https:/ / doi. org/10.3916/C44-2015-12

Fisher B. W., Gardella J. H., \& Teurbe-Tolon A. R. (2016). Peer cybervictimization among adolescents and the associated internalizing and externalizing problems: A meta-analysis. Journal of Youth and Adolescence, 45(9), 1727-1743. https:/ / doi.org/10.1007/s10964-016-0541-z

Fletcher A., Fitzgerald-Yau N., Jones R., Allen E., Viner R. M., \& Bonell C. (2014). Brief report: Cyberbullying perpetration and its associations with socio-demographics, aggressive behavior at school, and mental health outcomes. Journal of Adolescence, 37(8), 1393-1398. https:/ / doi.org/10.1016/j.adolescence.2014.10.005

Gámez-Guadix M., Orue I., Smith P. K., \& Calvete E. (2013). Longitudinal and reciprocal relations of cyberbullying with depression, substance use, and problematic internet use among adolescents. Journal of Adolescent Health, 53(4), 446-452. https:/ / doi.org/ 10.1016/j.jadohealth.2013.03.030

Garaigordobil M. (2013). Cyberbullying. Screening de acoso entre iguales. Screening del acoso escolar presencial (bullying) y tecnológico (cyberbullying) [Cyberbullying. Screening of peer-harassment. Screening of face-to-face and technological bullying]. Madrid, Spain: TEA.

Garaigordobil M. (2015). Cyberbullying in adolescents and youth in the Basque Country: Prevalence of cybervictims, cyberaggressors, and cyberobservers. Journal of Youth Studies, 18(5), 569-582. https:/ / doi.org/10.1080/13676261. 2014.992324

Garaigordobil M. (2017). Bullying y cyberbullying: Definición, prevalencia, consecuencias y mitos [Bullying and cyberbullying: definition, prevalence, consequences and myths]. Barcelona, Spain: Fundació per la Universitat Oberta de Catalunya.

García-Fernández C. M., Romera-Félix E. M., \& OrtegaRuiz R. (2016). Relaciones entre el bullying y el cyberbullying: prevalencia y co-ocurrencia [Relations between bullying and cyberbullying: Prevalence and co-ocurrence]. Pensamiento Psicológico, 14(1), 49-61. https://doi.org/10.11144/Javerianacali.PPSI14-1.rbcp

Gini G., Card N. A., \& Pozzoli T. (2018). A meta-analysis of the differential relations of traditional and cybervictimization with internalizing problems. Aggressive Behavior, 44(2), 185-198. https:/ / doi.org/10.1002/ ab. 21742

Guilheri J., Cogo-Moreira H., Kubiszewski V., Yazigi L., \& Andronikof A. (2015). Validité de construit du questionnaire rBVQ d'Olweus pour l'évaluation du harcèlement scolaire (bullying) auprès d'élèves français de cycle 3 [Bullying in school: Construct validity of the French version of the Olweus revised Bully/victim Questionnaire]. Neuropsychiatrie de l'Enfance et de l'Adolescence, 63(4), 211-217. https:/ / doi.org/10.1016/ j.neurenf.2015.01.010
Holt M. K., Vivolo-Kantor A. M., Polanin J. R., Holland K. M., DeGue S., Matjasko J. L., ... Reid G. (2015). Bullying and suicidal ideation and behaviors: A metaanalysis. Pediatrics, 135(2), e496-e509. https: / / doi. org/10.1542/peds.2014-1864

Instituto Nacional de Estadística. (2016) Press note from the 6th of October of 2016. Retrieved from http:/ / www.ine. es/prensa/np991.pdf

Iossi-Silva M., Pereira B., Mendonça D., Nunes B., \& de Oliveira W. A. (2013). The involvement of girls and boys with bullying: An analysis of gender differences. International Journal of Environmental Research and Public Health, 10(12), 6820-6831. https:/ / doi.org/10.3390/ ijerph10126820

Irakas-Sistema Ebaluatu eta Ikertzeko Erakundea-Instituto Vasco de Evaluación e Investigación Educativa (ISEI-IVEI) (2017). Maltrato entre iguales 2016 [Harrasment among peers 2016]. Retrieved from http:/ / www.isei-ivei. hezkuntza.net/c/document_library/get_file?uuid=842227f3b73c-4d22-b3b2-6dcb1af7609e\&groupId =635622

Jung Y.-E., Leventhal B., Kim Y. S., Park T. W., Lee S.-H., Lee M., ... Park J.-II. (2014). Cyberbullying, problematic internet use, and psychopathologic symptoms among Korean youth. Yonsei Medical Journal, 55(3), 826-830. https:/ / doi.org/10.3349/ymj.2014.55.3.826

Kokkinos C. M., Antoniadou N., Dalara E., Koufogazou A., \& Papatziki A. (2013). Cyber-bullying, personality and coping among pre-adolescents. International Journal of Cyber Behavior, Psychology and Learning, 3(4), 55-69. https://doi.org/10.4018/ijcbpl.2013100104

Kowalski R. M., Giumetti G. W., Schroeder A. N., \& Lattanner M. R. (2014). Bullying in the digital age: A critical review and meta-analysis of cyberbullying research among youth. Psychological Bulletin, 140(4), 1073-1137. https:/ / doi.org/10.1037/a0035618

Kowalski R. M., \& Limber S. P. (2013). Psychological, physical, and academic correlates of cyberbullying and traditional bullying. Journal of Adolescent Health, 53(1), S13-S20. https://doi.org/10.1016/j.jadohealth. 2012.09.018

Kowalski R. M., Limber S. P., \& McCord A. (2018). A developmental approach to cyberbullying: Prevalence and protective factors. Aggression and Violent Behavior. https://doi.org/10.1016/j.avb.2018.02.009

Leung A. N.-M., \& McBride-Chang C. (2013). Game on? Online friendship, cyberbullying, and psychosocial adjustment in Hong Kong Chinese children. Journal of Social and Clinical Psychology, 32(2), 159-185. https:/ / doi. org/10.1521/jscp.2013.32.2.159

Navarro R., Yubero S., \& Larrañaga E. (2015). Psychosocial risk factors for involvement in bullying behaviors: Empirical comparison between cyberbullying and social bullying victims and bullies. School Mental Health, 7(4), 235-248. https:/ / doi.org/10.1007/s12310015-9157-9

Pabian S., Vandebosch H., Poels K., van Cleemput K., \& Bastiaensens S. (2016). Exposure to cyberbullying as a bystander: An investigation of desensitization effects among early adolescents. Computers in Human Behavior, 62, 480-487. https://doi.org/10.1016/j.chb.2016.04.022 
Price M., Chin M. A., Higa-McMillan C., Kim S., \& Frueh B. C. (2013). Prevalence and internalizing problems of ethnoracially diverse victims of traditional and cyber bullying. School Mental Health, 5, 183-191. https:/ / doi. org/10.1007/s12310-013-9104-6

Rice E., Petering R., Rhoades H., Winetrobe H., Goldbach J. Plant A., Kordic T. (2015). Cyberbullying perpetration and victimization among middle-school students. American Journal of Public Health, 105(3), e66-e72. https: / doi.org/10.2105/AJPH.2014.302393

Shin H. H., Braithwaite V., \& Ahmed E. (2016). Cyber- and face-to-face bullying: Who crosses over? Social Psychology of Education, 19(3), 537-567. https:/ /doi.org/10.1007/ s11218-016-9336-Z

Shujja S., Att M., \& Shujjat J. M. (2014). Prevalence of bullying and victimization among sixth graders with reference to gender, socio-economic status and type of schools. Journal of Social Sciences, 38(2), 159-165. https:/ / doi.org/10.1080/09718923.2014.11893246

Ttofi M. M., \& Farrington D. P. (2011). Effectiveness of school-based programs to reduce bullying: A systematic and meta-analytic review. Journal of Experimental Criminology, 7, 27-56. https://doi.org/10.1007/ s11292-010-9109-1

Williams K. R., \& Guerra N. G. (2007). Prevalence and predictors of internet bullying. Journal of Adolescent Health, 41(6), S14-S21. https:/ / doi.org/10.1016/ j.jadohealth.2007.08.018

Yeager D. S., Fong C. J., Lee H. Y., \& Espelage D. L. (2015). Declines in efficacy of anti-bullying programs among older adolescents: Theory and a three-level meta-analysis. Journal of Applied Developmental Psychology, 37, 36-51. https://doi.org/10.1016/j.appdev. 2014.11.005 